\title{
Exergy Based Analysis for the Environmental Control and Life Support Systems of the International Space Station
}

\author{
Kirk A. Clem ${ }^{1}$, George J. Nelson, Ph.D. ${ }^{2}$ and Bryan L. Mesmer, Ph.D. ${ }^{3}$ \\ University of Alabama in Huntsville, Huntsville, Alabama, 35899 \\ Michael D. Watson, Ph.D. ${ }^{4}$ and Jay L. Perry ${ }^{5}$ \\ NASA, George C. Marshall Space Flight Center, Huntsville, Alabama, 35812
}

\begin{abstract}
When optimizing the performance of complex systems, a logical area for concern is improving the efficiency of useful energy. The energy available for a system to perform work is defined as a system's exergy content. Interactions between a system's subsystems and the surrounding environment can be accounted for by understanding various subsystem exergy efficiencies. Exergy balance of reactants and products, and enthalpies and entropies, can be used to represent a chemical process. Heat transfer exergy represents heat loads, and flow exergy represents system flows and filters. These elements allow for a system level exergy balance. The exergy balance equations are developed for the subsystems of the Environmental Control and Life Support (ECLS) system aboard the International Space Station (ISS). The use of these equations with system information would allow for the calculation of the exergy efficiency of the system, enabling comparisons of the ISS ECLS system to other systems as well as allows for an integrated systems analysis for sytem optimization.
\end{abstract}

\section{Nomenclature}

$\begin{array}{ll}\alpha_{A} & =\text { transfer coefficient } \\ \Delta t & =\text { change in time }[\mathrm{s}] \\ \Delta X & =\text { change in exergy }[\mathrm{J}] \\ \eta & =\text { efficiency } \\ \eta_{A} & =\text { anode activation overpotential [V] } \\ \eta_{C} & =\text { cathode activation overpotential [V] } \\ \eta_{I} & =\text { overpotential due to interfacial resistance }[\mathrm{V}] \\ \eta_{S P E} & =\text { overpotential due to electrolyte membrane }[\mathrm{V}] \\ F & =\text { Faraday's Constant }[96485 \mathrm{C} / \mathrm{mol}] \\ h & =\text { specific enthalpy }[\mathrm{J} / \mathrm{kg}] \\ H_{2} & =\text { Hydrogen } \\ H_{2} O & =\text { Water } \\ i & =\text { current density }\left[\mathrm{A} / \mathrm{m}^{2}\right] \\ i_{A O} & =\text { anode exchange current density }\left[\mathrm{A} / \mathrm{m}^{2}\right] \\ i_{C O} & =\text { cathode exchange current density }\left[\mathrm{A} / \mathrm{m}^{2}\right] \\ I & =\text { total current }[\mathrm{A}] \\ L_{B} & =\text { membrane thickness }[\mathrm{m}] \\ \dot{m} & =\text { mass flow rate }[\mathrm{kg} / \mathrm{s}] \\ \dot{N} & =\text { molar flow rate }[\mathrm{mol} / \mathrm{s}] \\ N I V & =\text { Nitrogen Isolation } \mathrm{Valve} \\ v_{e} & =\text { stoichiometric coefficient of electrons }\end{array}$

\footnotetext{
${ }^{1}$ Student, Department of Industrial and Systems Engineering and Engineering Management.

${ }^{2}$ Assistant Professor, Department of Mechanical and Aerospace Engineering.

${ }^{3}$ Assistant Professor, Department of Industrial and Systems Engineering and Engineering Management.

${ }^{4}$ Flight Systems Engineer, Systems Engineering Management Office/EE11.

${ }^{5}$ Lead Engineer, Environmental Control Systems, Space Systems Dept./ES62.
} 


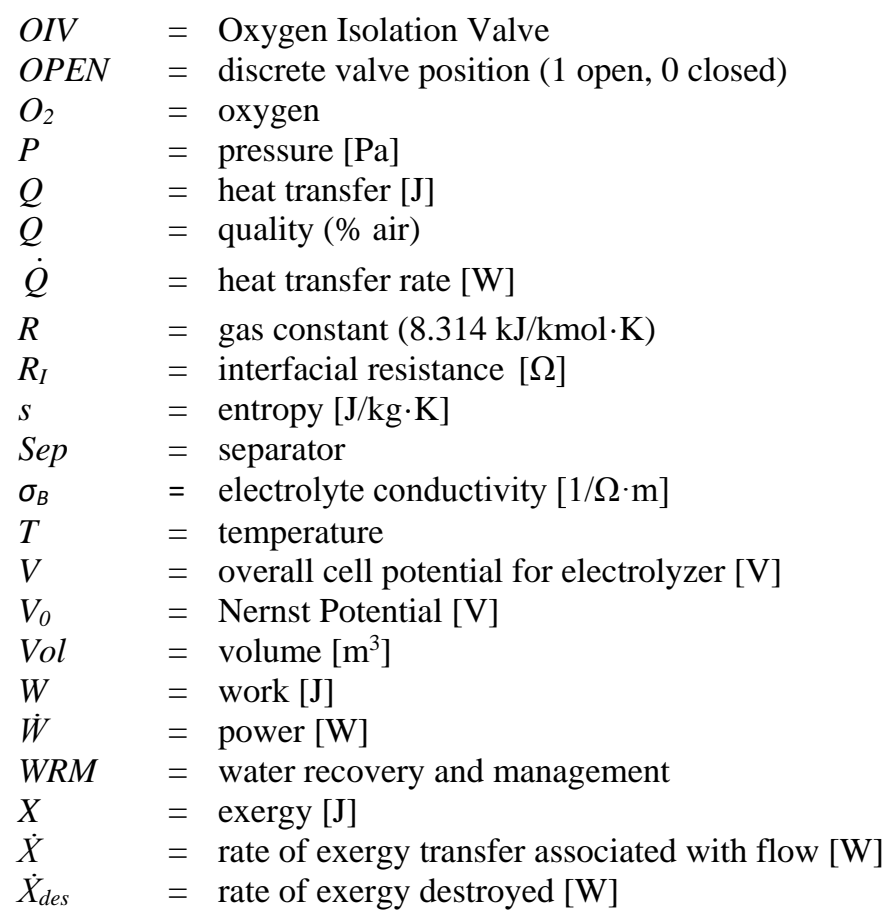

\section{Introduction}

$\mathrm{T}$ HE subsystems that make up the Environmental Control and Life Support (ECLS) system aboard the International Space Station (ISS) perform multiple functions. Cabin atmospheric regulation and revitalization, waste gas removal, oxygen generation, temperature and humidity control, urine processing, and water recovery are a mere handful of system processes that may be broken down and analyzed individually. The maximum work output attainable by each subsystem in relation to the dead state (i.e., reference state) of a specified operating environment may be expressed as a particular subsystem's exergy. For the purposes of this study, exergy may be thought of as a "common currency" for a system to perform work. Exergy provides a system-wide attribute that can be used to measure performance of all subsystems, and relates subsystem products (outputs) to subsystem reactants (inputs). ${ }^{1}$ An exergy balance describes the process that reactants and products undergo related to their enthalpies and entropies. Forms of exergy examined in this paper include heat transfer exergy, fluid flow exergy, and electrical work exergy. In this paper the exergy balance equation incorporating an exergy analysis of all subsystems of the ECLS is developed. These balances can be used to determine the efficiency of the system as a whole.

\section{Overview of ECLS for Purposes Beyond Low Earth Orbit}

As crewed space exploration objectives expand beyond lowEarth orbit, the ECLS system must safely enable nearly autonomous missions within an energy and resource efficient architecture. The ECLS systems of the future must be capable of operating for 500 to 1200 days with no Earth-based logistics resupply and be highly reliable and maintainable. The ECLS systems of the future, however, will possess many functional similarities to the system deployed aboard the ISS; therefore, studying the ISS
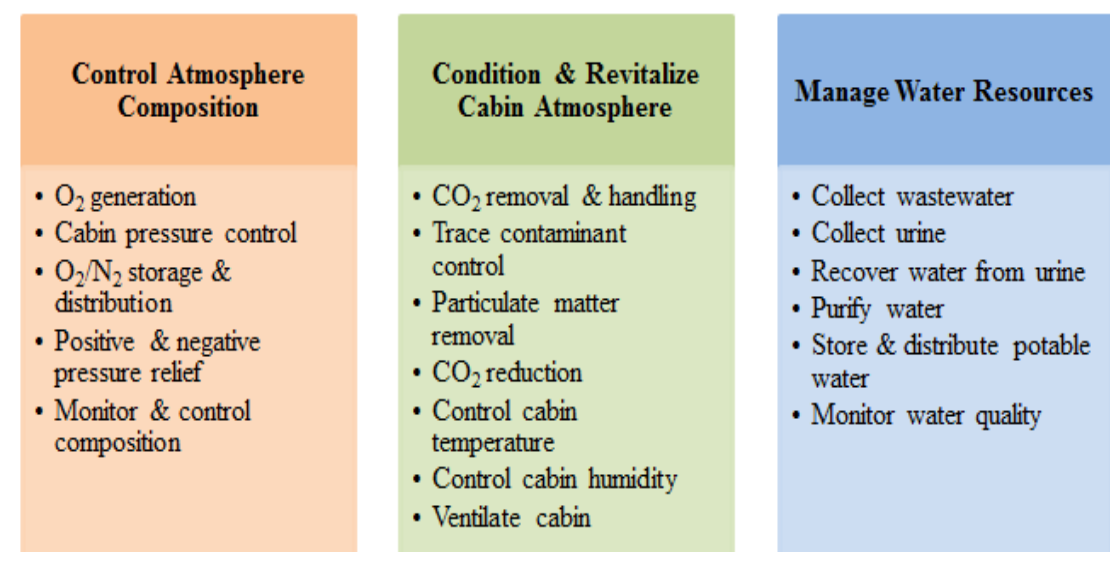

Figure 1. Functions provided by the ECLS system. 
ECLS system provides important insight. The principal functions that ECLS systems must provide for long duration missions are presented by Fig. 1.

The interfaces between these functions, illustrated by Fig. 2, will likely be common between the ISS and exploration missions. As such, the ISS ECLS not only serves as the technical basis for exploration ECLS system architectures, but also serves as a unique developmental laboratory to test candidate technologies and system performance evaluation techniques that can help improve the ECLS system design over the ISS state-of-the-art. Applying exergy metrics to ECLS systems, using the ISS ECLS system architecture as the starting model, may yield a new tool for optimizing the system beyond the traditional mass, power, and volume objectives.

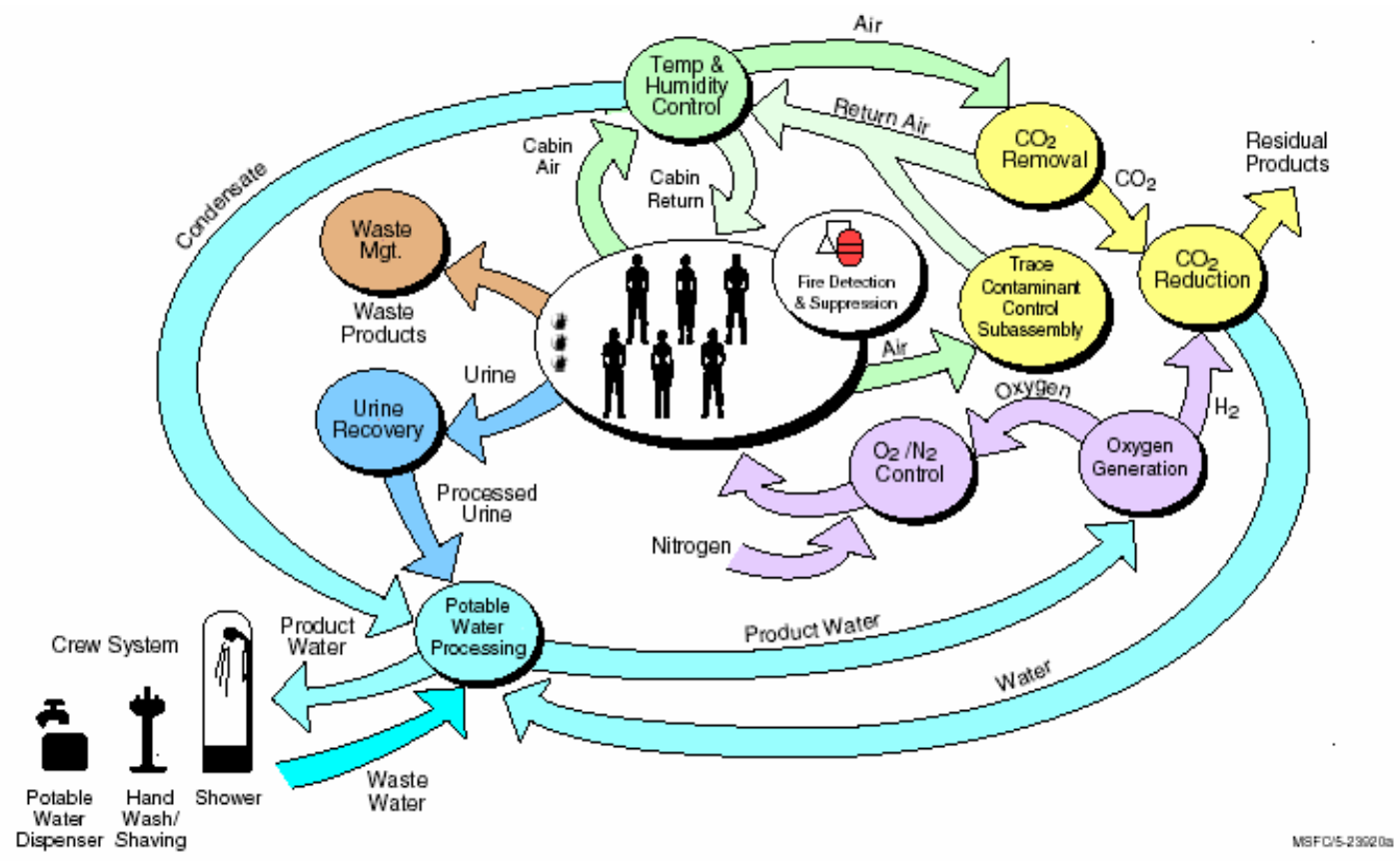

Figure 2. Functional interactions within an ECLS system architecture.

\section{Background}

\section{A. Exergy}

Exergy, a measure of work potential, is derived from the first and second laws of thermodynamics. The first law of thermodynamics states that there is a constant quantity of energy in the universe and asserts that energy is neither created nor destroyed but may be transformed. Thus the first law, a law of conservation, allows the engineer to track energy through a process. The second law of thermodynamics is concerned with the degradation of energy during a process. The relationship between first and second law analyses is seen in Fig. 3. Entropy generation and the lost ability to perform work suggest that the energy efficiency of a system may be improved. ${ }^{2}$

Corresponding to exergy, the maximum useful work that can be produced as a system performs a process between two specified states is identified as reversible work. In the case of reversible work, a system can rejuvenate itself to its original state in an impromptu fashion. This phenomenon does not occur in nature as real processes are irreversible. Additional energy is required to overcome losses and restore a system to its initial regime, and entropy is generated.

Many different fields have shown that there is much value to be gained by studying how exergy across a particular system changes through

First Law Analysis

\section{Usable Energy}

\section{Second Law Analysis Usable Energy Irreversible Energy}

Figure 3. First and second laws of thermodynamics. 
process. Production processes of many kinds can be modeled using exergy principles to describe resource and waste energy. ${ }^{3}$ These principles may be useful for other studies such as evaluating costs of different forms of energy ${ }^{4}$ such as power generation, ${ }^{5-9}$ and for studies of hypersonic aircraft. ${ }^{10}$ Camberos and Moorhouse have shown the use of exergy as a metric for modeling, constructing, and modification of aerospace vehicles. ${ }^{11}$ Doty, et al., has applied exergy to the early stages of turbine design enhancement. ${ }^{12}$ The work in this paper is in association with the NASA Systems Engineering Research Consortium. In previous work, the consortium has examined the use of exergy metrics in rocket systems. ${ }^{13-14}$ This previous work has shown an improved understanding of efficiencies when dealing with complex engineered systems. Future work with rocket systems will be examining the use of exergy in the optimization of rocket staging.

\section{B. Exergy Balance}

The general exergy rate balance for an open system, or control volume, is shown in Eq. 1.

$$
\frac{d X}{d t}=\sum_{i}\left(1-\frac{T_{0}}{T_{i}}\right) \dot{Q}_{i}+\left(\dot{W}_{\text {in }}-P_{0} \frac{d V o l}{d t}-\dot{W}_{\text {out }}\right)+\sum_{i} \dot{m} \psi_{\text {in }}-\sum_{i} \dot{m} \psi_{\text {out }}-\dot{X}_{\text {des }}
$$

On the right hand side of Eq. 1, $T_{0}$ represents the temperature of an environment, $Q$ is the rate of heat transfer in and out, $W$ is power in and out, $P_{0}$ is the pressure of the environment, $\mathrm{Vol}$ is the volume of the initial and final states, and $\psi$ represents a rate of exergy transfer by the fluid shown in Eq. 2 . The exergy transfer rates are associated with either mass flow into the system, mass flow out of the system, or exergy destruction associated with irreversibility in the system. For the ECLS system, the cabin is taken as the reference environment unless otherwise stated.

$$
\psi=h-T_{0} s+\frac{V^{2}}{2}+g z
$$

On the right hand side of Eq. 2, $\mathrm{h}$ is the enthalpy of the fluid stream, $\mathrm{T}_{0}$ is the reference temperature (i.e., cabin temperature), $\mathrm{s}$ is the entropy of the fluid stream, $\mathrm{v}$ is the velocity of the fluid stream, $\mathrm{g}$ is the gravitational constant (at the reference orbit altitude), and $\mathrm{z}$ is the change in height.

The left hand side of Eq. 1 represents the exergy stored within the system. Under steady state operation, this storage term, and the change in system volume with time, are eliminated. This condition gives the following steady state exergy balance for an open system.

$$
\dot{X}_{\text {des }}=\sum_{i}\left(1-\frac{T_{0}}{T_{i}}\right) \dot{Q}_{i}+\left(\dot{W}_{\text {in }}-\dot{W}_{\text {out }}\right)+\sum_{i} \dot{m} \psi_{\text {in }}-\sum_{i} \dot{m} \psi_{\text {out }}
$$

For a real system operating in the presence of irreversibility this exergy destruction will be positive. Eq. 3 indicates that under steady state operation the rate of exergy destroyed is balanced by the exergy transferred through work, heat transfer, and fluid flow. Under a limited set of inlet and exit conditions, an ideal case may be constructed such that the right hand side of the equation yields $\dot{X}_{d e s}=0$. This condition is associated with reversible operation of the system.

\section{Exergy Efficiency}

Under ideal, reversible operation no exergy is destroyed. The exergy balance in Eq. 3 can be recast to define the reverisble power production, Eq. 4. Here it is important to note that this reversible power is treated as a net power out of the system.

$$
\dot{W}_{\text {rev }}=\sum_{i}\left(1-\frac{T_{o}}{T_{i}}\right) \dot{Q}_{i}+\sum_{i} \dot{m} \psi_{\text {in }}-\sum_{i} \dot{m} \psi_{\text {out }}
$$

Comparing the actual power produced in the presence of exergy destruction to reversible power production provides a means for defining the system exergy efficiency. The overall exergy efficiency for any system is given by Eq. 5 .

$$
\eta_{\text {exergy }}=\frac{\text { Exergy Recovered }}{\text { Exergy Expended }}=1-\frac{\text { Exergy Destroyed }}{\text { Exergy Expended }}
$$

In Eq. $5, \dot{W}_{\text {actual }}$ is associated with exergy that is effectively used by the real system to generate power and $\dot{X}_{\text {des }}$ is associated with the loss term observed in the exergy balance equation. As defined in Eq. 4, the reversible power 
represents the maximum attainable power for a given set of environmental conditions, which corresponds to the absence of irreversibility during operation. The exergy efficiency equation allows for the ranking of the various subsystems from most thermodynamically efficient to least thermodynamically efficient. The system-wide metric of exergy efficiency is applicable to all engineering disciplines. For a given system analyzed on a rate basis, the maximum exergy efficiency corresponds to the minimum exergy destruction rate.

The ECLS system aboard the ISS is composed of various subsystems that perform functions such as atmospheric revitalization, waste management, and temperature and humidity control. ${ }^{15}$ This paper will develop the exergy balance equations for the following subsystems-Atmosphere Control and Supply (ACS), Atmosphere Revitalization (AR), Temperature and Humidity Control (THC), and Waste Recovery and Management (WRM). The objectives for this work are to simplify known exergy equations used to model the subsystems and add the product and reactant terms for the chemical processes. When performing this process, it will be important to note that for a serial string of processing stages, the intermittent values cancel whereby the output of one stage is the input to the next stage. Thus, the input to the subsystem and the output of the subsystem will be known with intermediate steps cancelling. To understand the interactions in the subsystem, a model incorporating exergy is created in Matlab ${ }^{\circledR}$. The Matlab ${ }^{\circledR}$ models enable future analysis of the subsystems with real-world data in terms of efficiency and enable optimization of the subsystem in future work. The following presents the exergy models developed for the ISS ECLS system.

\section{Exergy Analysis of ECLS Subsystems}

This paper first presents a detailed examination of an assembly within the AR subsystem to illustrate the detailed process for developing exergy models. This assembly, the Oxygen Generation Assembly (OGA), is highly detailed to provide the logical flow used in forming the exergy balances for the other subsystems examined. Following the detailed treatment of the OGA, each ECLS subsystem is described and their exergy balance equations are developed.

\section{A. Exergy Analysis of the Oxygen Generation Assembly}

The OGA is an assembly within the ARS. Equation 6 demonstrates the exergy relationships involved for the OGA.

$$
\begin{gathered}
\dot{\mathrm{X}}_{\text {Des, OGA }}=\dot{\mathrm{W}}_{\text {electrolyzer }}-\dot{m}_{\text {O2,o2 Sep }}\left(h_{O 2, \text { out }}-T_{\text {cabin }} S_{O 2, \text { out }}\right)-\dot{m}_{H 2, H 2 S e p}\left(h_{H 2, \text { out }}-T_{\text {cabin }} S_{H 2, o u t}\right) \\
+\dot{m}_{H 2 O, W R M}\left(h_{H 2 O, W R M}-T_{\text {cabin }} s_{H 2 O, W R M}\right)
\end{gathered}
$$

The term on the left hand side of the equation represents the rate of exergy destruction throughout electrolysis. The first term on the right hand side of the equation represents the power input from the water electrolyzer. The second term represents the enthalpy-entropy difference of oxygen $\left(\mathrm{O}_{2}\right)$ multiplied by the oxygen mass flow rate out of the $\mathrm{O}_{2}$ separator. The third term represent the enthalpy-entropy difference of hydrogen $\left(\mathrm{H}_{2}\right)$ multiplied by the hydrogen mass flow rate out of the $\mathrm{H}_{2}$ separator. The fourth term represents the enthalpy-entropy difference of water multiplied by the mass flow rate of water entering the electrolyzer.

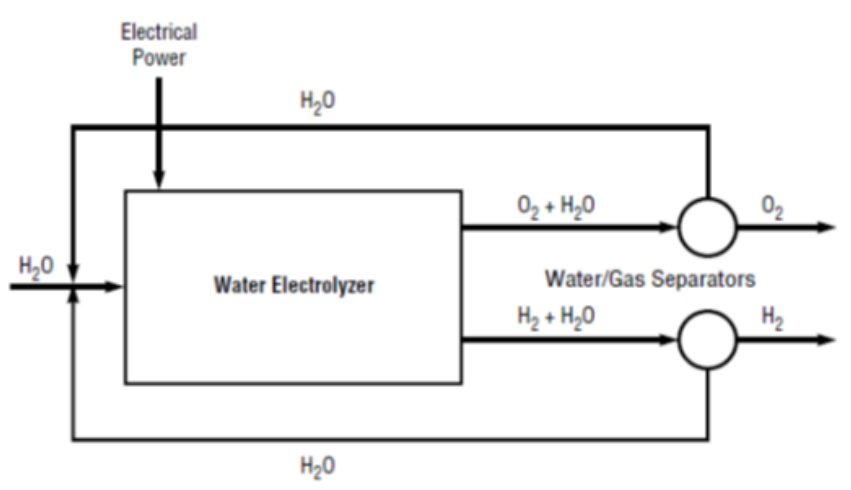

Figure 4. Simplified OGA process schematic.

A simplified schematic of the OGA is shown in Fig. 4. Water enters the assembly from the ISS potable water bus through the Water Assembly On-orbit Replacement Unit (ORU). An Inlet Deionizing (DI) Bed serves as an iodine remover and as a coalescer for the removal of gas bubbles from the feed water. Should gas bubbles be detected past the DI bed by a downstream gas sensor, a three-way valve sends the feed water to a waste water bus. This prevents any $\mathrm{O}_{2}$ that may be present in the feed water from mixing with any $\mathrm{H}_{2}$. Electrolysis takes place in a Hydrogen Dome ORU where water molecules are disassociated into $\mathrm{O}_{2}$ and $\mathrm{H}_{2}$ gas. A Rotary Separator Accumulator (RSA) is also located within the hydrogen dome. The RSA removes $\mathrm{H}_{2}$ that leaves the cathode from water which is recirculated by a positive displacement pump ORU. The removed $\mathrm{H}_{2}$ is then sent to a Sabatier-based carbon dioxide $\left(\mathrm{CO}_{2}\right)$ reduction process or is vented to space. The Power Supply Module (PSM) ORU powers the OGA electrolysis cell stack providing 10-55 amps of current during process mode, and 1.0 amps during standby mode which produces a $2 \% \mathrm{O}_{2}$ rate. This power supply allows for a nominal $\mathrm{O}_{2}$ 
production rate of $5.4 \mathrm{~kg} / \mathrm{day}$ which is enough to support four crewmembers. A maximum oxygen production rate of $9.2 \mathrm{~kg} /$ day may be achieved which provides enough oxygen to sustain seven crewmembers. ${ }^{16}$

A goal for conducting thermodynamic analysis of $\mathrm{O}_{2}$ and $\mathrm{H}_{2}$ generating electrolyzers is to identify key losses so that system performance may be optimized. Water electrolyzers run in an exothermic mode. Heat production that occurs within the electrolytic cells is caused by irreversible losses. These losses stem from overpotentials which exceed the thermal energy demand. If electrical energy is the dominant energy input, exergy efficiency will be almost identical to the system's energy efficiency. Meng et.al has identified parameters that would improve the exergy efficiency of water electrolyzers including reducing and controlling operating temperature, increasing current density, increasing electrolyte thickness, and decreasing electrode catalytic activity. ${ }^{17}$

Valverde et al. ${ }^{18}$ proposed a simple model for low-pressure water electrolyzers. The model provides enough precision for simulation of electrolchemical and thermal output flow behaviors. Choi et al. performed water electrolysis analysis using a simple model based on Butler-Volmer kinetics for electrodes and transport resistance in polymer electrolyte. The model demonstrates the behavior of applied thermal voltage and current density in terms of Nernst potential, exchange current desities, and polymer elctrolyte conductivity. Analyzed with in the model are overpotential and resistances at the anode and cathode, as well as overpotential due to ohmic losses. ${ }^{19}$

During electrolysis, water and $\mathrm{O}_{2}$ escape from the anode of the electrolytic cell, and $\mathrm{H}_{2}$ is produced from the cell's cathode. Their corrsponding mass balances are written as follows:

$$
\begin{aligned}
& \dot{N}_{H 2 O, \text { in }}-\dot{N}_{H 2 O, \text { out }}=\frac{i \mathrm{~A}}{2 \mathrm{~F}} \\
& \dot{N}_{H 2, \text { in }}-\dot{N}_{H 2, \text { out }}=-\frac{i \mathrm{~A}}{2 F} \\
& \dot{N}_{O 2, \text { in }}-\dot{N}_{O 2, \text { out }}=-\frac{i A}{4 F}
\end{aligned}
$$

The overall electrochemical reaction at the anode may be obtained by encorporating the Butler-Volmer expression: ${ }^{19}$

$$
i=i_{A 0}\left[\exp \left(\frac{\alpha_{A} v_{e-}-F \eta_{A}}{R T}\right)-\exp \left(-\frac{\left(1-\alpha_{A}\right) v_{e-F} \eta_{A}}{R T}\right)\right]
$$

If the effective transfer coefficient is assumed to be 0.5 , and the stoichiometric coefficient of electrons in the anode is assumed to be 2 , then the anode overpotential takes the form as follows:

$$
\eta_{\mathrm{A}}=\frac{R T}{F} \sinh ^{-1}\left(\frac{i}{2 i_{A 0}}\right)
$$

If the effective transfer coefficient, $\alpha_{A}$, is assumed to be 0.5 , but now the stoichiometric coefficient of electrons in the cathode is assumed to be -2 , then the cathode overpotential takes the form as follows:

$$
\eta_{C}=-\frac{R T}{F} \sinh ^{-1}\left(\frac{i}{2 i_{A 0}}\right)
$$

For determination of the electrochemical potential of the electrolysis cell the Nernst potential, anode overpotential, cathode overpotential, overpotential due to membrane, and interfacial overpotential due to resistance must be determined. The overall cell potential takes the following form:

$$
V=V_{0}+\eta_{A}-\eta_{C}+\eta_{S P E}+\eta_{I}
$$

The Nernst potential is empirically given as:

$$
V_{0}=1.23-0.9 E-3(T-298)+2.3 \frac{R T}{4 F} \log \left(P_{H 2}{ }^{2} P_{o 2}\right)
$$

Overpotential due to membrane resistance is given as follows:

$$
\eta_{S P E}=\left(\frac{L_{B}}{\sigma_{B}}\right) i
$$

Interfacial overpotential is calculated as follows:

$$
\eta_{I}=R_{I} I
$$

Here, $R_{I}$ is the interfacial resistance of the electrolyzer and $I$ is the total applied current. Once the overall required cell potential is determined, the required power is obtained:

$$
\dot{W}_{\text {ele }}=V I
$$

After defining the required power required for electrolysis, the rate of exergy destroyed by the oxygen generation process may be determined as follows:

$$
\begin{gathered}
\dot{X}_{D E S, O G A}=\dot{W}_{E L E}-\dot{m}_{\text {O2,O2Sep }}\left(h_{O 2, \text { out }}-T_{\text {cabin }} s_{O 2, \text { out }}\right)-\dot{m}_{H 2, H 2 S e p}\left(h_{H 2, \text { out }}-T_{\text {cabin }} s_{H 2, \text { out }}\right) \\
+\dot{m}_{H 2 O . W R M}\left(h_{H 2 O . W R M}-T_{\text {cabin }} s_{H 2 O . W R M}\right) \\
6
\end{gathered}
$$




\section{B. Exergy Analysis of the Atmosphere Revitalization Subsystem}

The ARS removes $\mathrm{CO}_{2}$ and other trace gases produced by crewmembers and equipment offgassing that are potentially harmful to their health. The ARS also monitors the space station's atmosphere for major constituents- $\mathrm{O}_{2}, \mathrm{~N}_{2}, \mathrm{CO}_{2}$, methane $\left(\mathrm{CH}_{4}\right)$, and water vapor. The major assemblies within the ARS are the Carbon Dioxide Removal Assembly (CDRA), the Oxygen Generation Assembly (OGA), the Trace Contaminant Control Subassembly (TCCS), and the Major Constituent Analyzer (MCA).

\section{Carbon Dioxide Removal Assembly}

The CDRA is a 4-bed molecular sieve (4BMS) process which removes $\mathrm{CO}_{2}$ from the cabin atmosphere via adsorption using two zeolite $5 \mathrm{~A}$ molecular sieve pellet beds. The two beds operate in cycles allowing one bed to regenerate by desorption of $\mathrm{CO}_{2}$ while the other bed cycles through a $\mathrm{CO}_{2}$ adsorption process. This provides continuous operation for the removal of $\mathrm{CO}_{2}$. Water vapor is first adsorbed from the inlet gases onto beds of zeolite $13 \mathrm{X}$ and silica gel. The inlet duct to the CDRA interfaces downstream of a condensing heat exchanger where moisture is removed from the cabin atmosphere by condensation. Here, bulk moisture is removed, reducing the water load presented to the desiccant beds in the CDRA. Components within the CDRA include desiccant beds/ $\mathrm{CO}_{2}$ adsorbent beds, air selector and check valves, a pre-cooler, blower assembly, and an air save bump. ${ }^{20}$ The CDRA process may be analyzed holistically from an exergy perspective as follows:

$$
\begin{aligned}
& \dot{X}_{\text {des, } 4 B M S}=\dot{\mathrm{W}}_{\text {CO2 Valve Switches }}+\dot{\mathrm{W}}_{\text {CO2 sensors/electronics }}-\left[\dot { m } _ { \text { air,desiccant } 2 \text { out } } \left(\boldsymbol{h}_{\text {air, desiccant out }}-\right.\right. \\
& \left.T_{\text {cabin }} \boldsymbol{s}_{\text {air, desiccant out }}\right)-\dot{m}_{\text {air,CDRA in }}\left(\boldsymbol{h}_{\text {air,CDRA in }}-T_{\text {cabin }} \boldsymbol{s}_{\text {air,CDRA in }}\right)-\dot{m}_{\text {deposit }, \text { H2O }}\left(\frac{V_{H 2 O, C D R A}^{2}}{2}\right)- \\
& \left.\dot{m}_{\text {deposit } 2 \text {,H2O }}\left(\frac{V_{H 2 O, C D R A 2}^{2}}{2}\right)\right]_{\text {desiccants }}+\left[\dot{\mathrm{W}}_{\text {CDRA Blower }}-\left(1-\frac{T_{\text {cabin }}}{T_{\text {Blower }}}\right) \dot{\boldsymbol{Q}}_{C D R A \text { Blower }}\right]_{\text {Blower }}+ \\
& {\left[-\left(\frac{T_{\text {cabin }}-T_{\text {coolant }}}{T_{\text {coolant }}}\right) \dot{\boldsymbol{Q}}_{\text {CDRA precooler }}\right]_{\text {precooler }}+\left[\dot{m}_{\text {deposit,CO2 Sorbent }}\left(\frac{V_{\text {CO2,CDRA }}^{2}}{2}\right)\right]_{\text {CO2 Adsorptions }}+} \\
& \text { OPEN }_{A S}\left[\dot{\mathrm{W}}_{\text {AS pump }}-\left(\mathbf{1}-\frac{\boldsymbol{T}_{\text {cabin }}}{\boldsymbol{T}_{\text {AS Pump }}}\right) \dot{\boldsymbol{Q}}_{\text {AS pump }}-\dot{m}_{\text {air,Sorbent out }}\left(\left(\boldsymbol{h}_{\text {air,AS Pump out }}-\right.\right.\right. \\
& \left.\left.\left.T_{\text {cabin }} \boldsymbol{s}_{\text {air,AS Pump out }}\right)-\left(\boldsymbol{h}_{\text {air,AS Pump in }}-T_{\text {cabin }} \boldsymbol{s}_{\text {air,AS Pump in }}\right)\right)\right]_{\text {Air Save }}+\left[\dot{\mathrm{W}}_{\text {Co2 Sorbent Heater }}-\right. \\
& \left.O P E N_{C O 2 \text { Vent }} \dot{m}_{\text {deposit }, C O 2 \text { release }}\left(\boldsymbol{h}_{\text {air,Co2 release }}-T_{\text {cabin }} \boldsymbol{s}_{\text {air,CO2 release }}\right)\right]_{\text {Co2 desorption }}
\end{aligned}
$$

\section{Oxygen Generation Assembly}

The exergy analysis of the OGA was discussed previously in Section B.

\section{Trace Contaminant Control Subassembly}

The TCCS removes and disposes of gaseous contaminants. It is composed of a charcoal bed, flow meter, blower, catalytic oxidizer, and a sorbent bed. The charcoal bed contains a disposable activated carbon for removing compounds with larger molecular weights. The blower within the TCCS controls system airflow, and is designed similar to the blower in the CDRA. The catalytic oxidizer assembly contains palladium (Pd) on an alumina $\left(\mathrm{Al}_{2} \mathrm{O}_{3}\right)$ catalyst which converts carbon monoxide ( $\mathrm{CO}$ ), $\mathrm{CH}_{4}, \mathrm{H}_{2}$, and other compounds with low molecular weights that the charcoal bed is unable to absorb into $\mathrm{CO}_{2}$, water, and other acceptable compounds. The sorbent bed contains granular lithium hydroxide $(\mathrm{LiOH})$ to remove any undesirable acidic byproducts of catalytic oxidation such as hydrogen chloride $(\mathrm{HCl})$, chlorine $\left(\mathrm{Cl}_{2}\right)$, fluorine $\left(\mathrm{F}_{2}\right)$, nitrogen dioxide $\left(\mathrm{NO}_{2}\right)$, and sulfur dioxide $\left(\mathrm{SO}_{2}\right){ }^{20}$ The TCCS is analyzed from an exergy perspective as follows:

$$
\begin{aligned}
& \dot{X}_{d e s, T C C S}=\left[\dot{m}_{\text {air }, T C C S C B} \frac{v_{\text {air }, C B \text { out }}^{2}}{2}+\dot{m}_{\text {TCCS deposit }, \text { filter }}\left(\frac{v_{\text {air }, C B \text { in }}^{2}}{2}\right)-\dot{m}_{\text {air }, T C C S \text { in }} \frac{v_{\text {air }, C B \text { in }}^{2}}{2}\right]_{C B}+ \\
& {\left[\dot{\mathrm{W}}_{\text {TCCS Blower }}-\left(\mathbf{1}-\frac{\boldsymbol{T}_{\text {cabin }}}{\boldsymbol{T}_{\text {Blower }}}\right) \dot{\boldsymbol{Q}}_{\text {TCCS Blower }}-\dot{m}_{\text {air }, T C C S C B}\left(\left(\boldsymbol{h}_{\text {air }, T C C S} \text { Blower out }-\right.\right.\right.} \\
& \left.\left.\left.T_{\text {cabin }} \boldsymbol{s}_{\text {air,TCCS Blower out }}\right)-\left(\boldsymbol{h}_{\text {air,TCCS Blower in }}-T_{\text {cabin }} \boldsymbol{s}_{\text {air,TCCS Blower in }}\right)\right)\right]_{\text {Blower }}+
\end{aligned}
$$

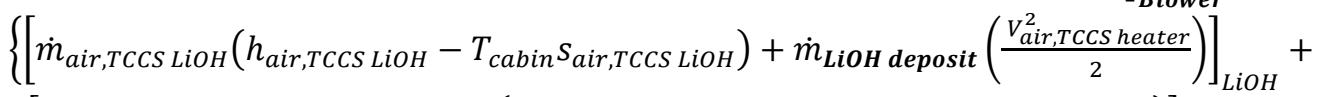

$$
\begin{aligned}
& {\left[\dot{\mathrm{W}}_{\text {HTCO heater }}-\dot{m}_{\text {air,blower HTCO }}\left(h_{\text {air,TCCS Blower out }}-T_{\text {cabin }} S_{\text {air }, \text { TCCS Blower out }}\right)\right]_{\text {heater }}+} \\
& {\left[-m_{\text {air,blower orifice }}\left(h_{\text {air,TCCS orifice out }}-T_{\text {cabin }} S_{\text {air,TCCS orifice out }}\right)-\right.} \\
& \left.\left.\dot{m}_{\text {air,blower orifice }}\left(h_{\text {air,TCCS Blower out }}-T_{\text {cabin }} S_{\text {air }, T C C S} \text { Blower out }\right)\right]_{\text {orifice }}\right\}
\end{aligned}
$$

American Institute of Aeronautics and Astronautics 


\section{Major Constituent Analyzer}

The MCA functions by drawing samples past a single-focusing magnetic sector mass spectrometer where drawn gas molecules are ionized by an ion source. The ionized molecules are then accelerated by an electron field and move into a shaped magnetic field where they may be dispersed by molecular weight. Dispersed ion beams are then focused into Faraday current collectors by resolving slits. Collected currents are proportional to partial pressures. Molecules that are not collected are absorbed by an ion pump. Air that is not able to enter the mass spectrometer is delivered to the ARS rack by pump. ${ }^{20}$ Exergy destroyed from the MCA is modeled as follows:

$$
\begin{aligned}
& \dot{X}_{\text {des }, M C A}=\left[\dot{\mathrm{W}}_{\text {MCA MS }}-\left(\boldsymbol{h}_{\text {air,MCA MS vent }}-T_{\text {space }} \boldsymbol{s}_{\text {air,MCA MCA vent }}\right)+\left(\boldsymbol{h}_{\text {air }, M C A M S \text { in }}-\right.\right. \\
& \left.\left.T_{\text {cabin }} \boldsymbol{S}_{\text {air,MCA MS in }}\right)\right]_{\text {MCA MS }}+\left[\dot{\mathrm{W}}_{\text {MCA pump }}-\left(\mathbf{1}-\frac{\dot{\boldsymbol{T}}_{\text {cabin }}}{\boldsymbol{T}_{\text {Blower }}}\right) \dot{\boldsymbol{Q}}_{G C \text { pump }}-\right. \\
& \dot{m}_{\text {air,MCA pump in }}\left(\left(\boldsymbol{h}_{\text {air,MCA pump out }}-T_{\text {cabin }} \boldsymbol{s}_{\text {air,MCA pump out }}\right)-\left(\boldsymbol{h}_{\text {air,MCA pump in }}-\right.\right. \\
& \left.\left.\left.T_{\text {cabin }} \boldsymbol{s}_{\text {air,MCA pump in }}\right)\right)\right]_{\text {MCA pump }}+\dot{\mathrm{W}}_{\text {MCA heater }}+\left[\boldsymbol{P}_{\text {cabin }}\left(\text { Vol }_{\text {air Tank Pres }}-\text { Vol }_{\text {cabin Pres }}\right)-\right. \\
& \left.T_{\text {cabin }}\left(\boldsymbol{s}_{\text {air Tank Pres }}-\boldsymbol{s}_{\text {air,cabin }}\right)\right] \frac{\Delta X}{\Delta t}{ }_{\boldsymbol{V} G A}
\end{aligned}
$$

\section{Exergy Analysis of the Atmosphere Control and Supply System}

The ACS subsystem performs multiple functions such as cabin pressure control, at mospheric composition control, $\mathrm{O}_{2} / \mathrm{N}_{2}$ partial pressure control, provides over- and under-pressure relief of any particular module, provides the ability to evacuate the atmosphere of any individual module, manual pressure equalization capability at module interfaces, and allows for internal distribution of $\mathrm{O}_{2}$ and $\mathrm{N}_{2}$ to ISS systems, crew, and payload interfaces at desired temperatures, pressures and flow rates. The ACS subsystem consists of the following components that are analyzed from an exergy perspective: pressure control assembly (PCA), $\mathrm{O}_{2}$ and $\mathrm{N}_{2}$ storage and distribution, manual pressure equalization valve (MPEV), $\mathrm{N}_{2}$ interface assembly (NIA), and airlock air save pump package. ${ }^{20}$ The ACS subsystem as a whole may be analyzed from an exergy perspective as follows:

$$
\begin{aligned}
& \dot{X}_{\text {des, }, A C S}=\left[\left(\boldsymbol{P}_{\text {cabin }}\left(\text { Vol }_{\text {O2 Tank Pres }}-\text { Vol }_{\text {cabin Pres }}\right)-T_{\text {cabin }}\left(\boldsymbol{s}_{\text {O2 Tank Pres }}-\boldsymbol{s}_{\text {air }, \text { cabin }}\right)\right)+\right. \\
& \left.\left(\boldsymbol{P}_{\text {cabin }}\left(V_{\text {ol }} l_{N 2 \text { Tank Pres }}-\operatorname{Vol}_{\text {cabin Pres }}\right)-T_{\text {cabin }}\left(\boldsymbol{s}_{N 2 \text { Tank Pres }}-\boldsymbol{s}_{\text {air,cabin }}\right)\right)\right] \frac{\Delta X}{\Delta t} \text { storage }- \\
& \left\{\left[\dot{m}_{O 2}\left(\frac{V_{O 2, i n}^{2}}{2}\right)+\dot{\mathrm{W}}_{\text {OIV }}+\dot{m}_{N 2}\left(\frac{V_{N 2, i n}^{2}}{2}\right)+\dot{\mathrm{W}}_{N I V}\right]_{R V}+\left[\dot { m } _ { O 2 } \left(\left(\boldsymbol{h}_{O 2, \text { in }}-\boldsymbol{h}_{\text {air,cabin }}\right)-T_{c a b i n}\left(\boldsymbol{s}_{O 2, \text { in }}-\right.\right.\right.\right. \\
& \left.\left.\left.\left.\boldsymbol{s}_{\text {air,cabin }}\right)\right)+\dot{m}_{N 2}\left(\left(\boldsymbol{h}_{N 2, \text { in }}-\boldsymbol{h}_{\text {air,cabin }}\right)-T_{\text {cabin }}\left(\boldsymbol{s}_{N 2, i n}-\boldsymbol{s}_{\text {air,cabin }}\right)\right)\right]_{\text {Mix Diff }}\right\}- \\
& \left\{\left[\boldsymbol{O P E N} N_{\text {MPEV }}\left(\dot{m}_{\text {air,MPEV }}\left(\boldsymbol{h}_{\text {air,cabin } 1}-\boldsymbol{h}_{\text {air,cabin balance }}\right)\right)\right]_{\text {Equalization }}+\right. \\
& {\left[\text { OPEN } _ { \text { VRIV } } \text { OPEN } \boldsymbol { N } _ { \text { VRCV } } \left(\dot { m } _ { \text { air,VRV } } \left(\left(\boldsymbol{h}_{\text {air,cabin }}-\boldsymbol{h}_{\text {air,sapce }}\right)-T_{\text {space }}\left(\boldsymbol{s}_{\text {air,cabin }}-\boldsymbol{s}_{\text {air,space }}\right)+\right.\right.\right.} \\
& \left.\left.\left.\left.\frac{V_{\text {air,vent }}^{2}}{2}\right)+\dot{\mathrm{W}}_{\text {VRIV }}+\dot{\mathrm{W}}_{\text {VRCV }}\right)\right]_{\text {Vent }}\right\}_{\text {Pres Reg }}+\dot{\mathrm{W}}_{\text {Elec Standby }}
\end{aligned}
$$

\section{Pressure Control Assembly}

The PCA controls and monitors the total pressure within the module by controlling oxygen and nitrogen partial pressures. The PCA allows for controlled venting to space of on board gasses, and provides controlled re-pressurization capability. The first component analyzed from the PCA is the mixing diffuser. Exergy destroyed within the mixing diffuser is defined by the changes in enthalpy, entropy, and kinetic energy. The mixing diffuser is fed by a mixing chamber which allows for gases to enter the cabin.

$$
\begin{aligned}
& \dot{X}_{D E S, D I F F U S E R}=\dot{m}_{\boldsymbol{O} 2}\left(\left(\boldsymbol{h}_{O 2, \text { in }}-\boldsymbol{h}_{\text {air,cabin }}\right)-T_{\text {cabin }}\left(\boldsymbol{s}_{\text {O2,in }}-\boldsymbol{s}_{\text {air,cabin }}\right)+\frac{\boldsymbol{v}_{\text {O2,oIV }}^{2}}{2}\right) \\
& +\dot{m}_{N 2}\left(\left(\boldsymbol{h}_{N 2, i n}-\boldsymbol{h}_{\text {air,cabin }}\right)-T_{\text {cabin }}\left(\boldsymbol{s}_{N 2, i n}-\boldsymbol{s}_{\text {air, }, \text { abin }}\right)+\frac{\boldsymbol{V}_{N 2, N I V}^{2}}{\mathbf{2}}\right)
\end{aligned}
$$

Gas flow through restrictors and interface valves contained within the PCA is next analyzed from an exergy perspective. Work performed when opening and closing restrictors and interface valves is a small change in kinetic energy, and the electrical power supplied to actuate the valves. 


$$
\dot{X}_{D E S, R E S T R I C T O R}=\dot{m}_{O 2}\left(\frac{v_{O 2, \text { in }}^{2}}{2}-\frac{v_{O 2, O I V}^{2}}{2}\right)+\dot{\mathrm{W}}_{O I V}+\dot{m}_{N 2}\left(\frac{v_{N 2, i n}^{2}}{2}-\frac{v_{N 2, N I V}^{2}}{2}\right)+\dot{\mathrm{W}}_{N I V}
$$

Vent Relief Valves (VRV) may be similarly analyzed from an exergy perspective as follows:

$$
\begin{gathered}
\dot{X}_{D E S, V R V}=O P E N_{V R I V} O P E N_{V R C V}\left(\dot { m } _ { \text { air,VRV } } \left(\left(h_{\text {air,cabin }}-h_{\text {air,sapce }}\right)\right.\right. \\
\left.\left.-T_{\text {space }}\left(s_{\text {air,cabin }}-s_{\text {air,space }}\right)+\frac{V_{\text {air }, \text { vent }}^{2}}{2}\right)+\dot{\mathrm{W}}_{V R I V}+\dot{\mathrm{W}}_{V R C V}\right)
\end{gathered}
$$

2. Oxygen and Nitrogen Storage and Distribution

The $\mathrm{O}_{2}$ and $\mathrm{N}_{2}$ storage and distribution systems consist of storage tanks, interface valves, and distribution lines which allow for controlled delivery of pressurized oxygen and nitrogen to required destinations within the spacecraft. Exergy stored within the $\mathrm{N}_{2}$ and $\mathrm{O}_{2}$ storage tanks may be modeled as follows:

$$
\begin{gathered}
\boldsymbol{X}_{\text {stored nitrogen }}=\left[\left(\boldsymbol{P}_{\text {cabin }}\left(\operatorname{Vol}_{N 2 \text { Tank Pres }}-\text { Vol }_{\text {cabin Pres }}\right)-T_{\text {cabin }}\left(\boldsymbol{s}_{N 2 \text { Tank Pres }}-\boldsymbol{s}_{\text {air, cabin }}\right)\right)\right]_{\text {Storage }} \\
\boldsymbol{X}_{\text {stored oxygen }}=\left[\left(\boldsymbol{P}_{\text {cabin }}\left(\text { Vol }_{\text {O2 Tank Pres }}-\text { Vol }_{\text {cabin Pres }}\right)-T_{\text {cabin }}\left(\boldsymbol{s}_{\text {O2 Tank Pres }}-\boldsymbol{s}_{\text {air,cabin }}\right)\right)\right]_{\text {Storage }}
\end{gathered}
$$

3. Manual Pressure Equalization Valve

The MPEVs, located in all hatches, are used when equalizing pressure in two adjacent pressurized modules. This equalization is performed prior to opening the hatches that separate the modules. Other applications for MPEVs include collecting atmosphere samples from, and to measure pressure within a module prior to opening a hatch. The rate of exergy destroyed when operating the MPEV occurs as follows:

$$
\dot{X}_{D E S, M P E V}=\boldsymbol{O P E} \boldsymbol{N}_{M P E V}\left(\dot{m}_{\text {air }, M P E V}\left(\left(\boldsymbol{h}_{\text {air,cabin } 1}-\boldsymbol{h}_{\text {air,cabin balance }}\right)\right)\right)
$$

\section{Nitrogen Interface Assembly}

The NIA is used to pressurize the accumulator as an interface to the Internal Thermal Control System (ITCS). The rate of exergy destroyed for the accumulator within the NIA is as follows:

$$
\dot{X}_{D E S, A C C U M U L A T O R}=\dot{m}_{N 2, \text { in }}\left(\boldsymbol{h}_{N 2, \text { in }}-T_{\text {cabin }} \boldsymbol{s}_{N 2, \text { in }}\right)-\dot{m}_{N 2, \text { out }}\left(\boldsymbol{h}_{N 2, \text { out }}-T_{\text {cabin }} \boldsymbol{s}_{N 2, \text { out }}\right)
$$

5. Airlock Air Save Pump Package

The airlock air save pump package reduces pressure in the entire airlock from 101.3 to $70.3 \mathrm{kPa}$ for extravehicular activity (EVA) campout prior to EVAs. The rate of exergy destroyed from operation of the air save pump is as follows:

$$
\begin{aligned}
\dot{\mathrm{X}}_{\text {Des,Air Save }}= & \boldsymbol{O P E} \boldsymbol{N}_{\text {AS }}\left[\dot{\mathrm{W}}_{\text {AS pump }}-\left(\mathbf{1}-\frac{\boldsymbol{T}_{\text {Cabin }}}{\boldsymbol{T}_{\text {Pump }}}\right) \dot{\boldsymbol{Q}}_{\text {AS pump }}-\dot{m}_{\text {air,Sorbent out }}\left(\left(\boldsymbol{h}_{\text {air,AS Pump out }}\right.\right.\right. \\
& \left.\left.\left.-T_{\text {cabin }} \boldsymbol{s}_{\text {air }, \text { AS Pump out }}\right)-\left(\boldsymbol{h}_{\text {air,AS Pump in }}-T_{\text {cabin }} \boldsymbol{s}_{\text {air }, \text { AS Pump in }}\right)\right)\right]
\end{aligned}
$$

\section{Exergy Analysis of the Temperature and Humidity Control System}

The THC system regulates the temperature and humidity levels within the atmosphere aboard the space station. Internal factors within the space station such as heat metabolically generated by crewmembers and equipment generated heat cause temperature to rise. Crew respiration and perspiration allows for humidity levels to increase. The THC system is set in place to regulate these internal factors. Components included within the THC system include the Common Cabin Air Assembly (CCAA), the Avionics Air Assembly (AAA), and the intermodule ventilation system (IMV). The CCAA provides temperature and humidity regulation for the cabin, the AAA provides cooled air and ventilation needed for the Fire Detection System, and air flow and the removal of $\mathrm{CO} 2$ and trace contaminants is provided by the IMV system to modules that do not have ARS or ACS equipment. Particulate filters rated to high efficiency particulate air (HEPA) standards are included within the THC system to remove particulate matter and microorganisms from the space station's atmosphere. ${ }^{20}$

1. Common Cabin Air Assembly

The CCAA consists of a fan assembly, condensing heat exchanger, and water separator for humidity regulation. The fan assembly's exergy rate balance equation is as follows:

$$
\begin{gathered}
\dot{X}_{d e s, C C A A \text { Fan }}=\dot{\mathrm{W}}_{\text {THC Fan }}-\left(\mathbf{1}-\frac{\boldsymbol{T}_{\text {cabin }}}{\boldsymbol{T}_{\text {Fan }}}\right) \dot{\boldsymbol{Q}}_{\text {THC Fan }}-\dot{m}_{\text {air }, \text { fanout }}\left(\left(\boldsymbol{h}_{\text {air }, \text { THC Fan Out }}-\right.\right. \\
\left.\left.T_{\text {cabin }} \boldsymbol{s}_{\text {air, THC Fan Out }}\right)-\left(\boldsymbol{h}_{\text {air, }, \text { THC Fan in }}-T_{\text {cabin }} \boldsymbol{s}_{\text {air }, \text { THC Fan in }}\right)\right)
\end{gathered}
$$

American Institute of Aeronautics and Astronautics 
The condensing heat exchanger is analyzed from an exergy perspective as follows:

$$
\begin{aligned}
& \dot{X}_{D E S, C C A A C H X}=k \dot{m}_{\text {dryair,fanout }}\left(\left(h_{\text {air }, T H C H X \text { in }}-T_{\text {cabin }} s_{\text {air }, T H C H X} \text { in }\right)-\left(h_{\text {air, } T H C H X} \text { out }-\right.\right.
\end{aligned}
$$

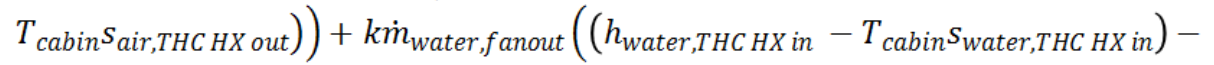

$$
\begin{aligned}
& \left.\left(h_{\text {water }, T H C \text { HX out }}-T_{\text {cabin }} S_{\text {water, } T H C \text { HX out }}\right)\right)-\left(\frac{T_{\text {cabin }}-T_{\text {coolant }}}{T_{\text {coolant }}}\right) \dot{Q}_{\text {THC TCS }}
\end{aligned}
$$

where

$$
\dot{m}_{\text {air,fanout }}=\dot{m}_{\text {dryair,fanout }}+\dot{m}_{\text {water,fanout }}
$$

and

$$
k=\frac{\dot{m}_{\text {air }, H X}}{\dot{m}_{\text {air,fanout }}}
$$

The CCAA's water separator may be modeled from an exergy perspective as follows:

where

$$
\begin{aligned}
& \dot{X}_{d e s, T H C W S}=\dot{\mathrm{W}}_{W S \text { elec }}+\dot{\mathrm{W}}_{\text {WS pump }}-\left(\mathbf{1}-\frac{\boldsymbol{T}_{\text {cabin }}}{T_{\text {pump }}}\right) \dot{\boldsymbol{Q}}_{W S \text { pump }}+\boldsymbol{k} \dot{m}_{\text {water,fanout }}\left(\boldsymbol{h}_{\text {water,THC WS in }}-\right. \\
& \left.T_{\text {cabin }} \boldsymbol{s}_{\text {water,THC WS in }}\right)-\dot{m}_{\text {water,WS out }}\left(\boldsymbol{h}_{\text {water,THC WS out }}-T_{\text {cabin }} \boldsymbol{s}_{\text {water,THC wS out }}\right)- \\
& \dot{m}_{\text {air,WS out }}\left(\boldsymbol{h}_{\text {air,WS out }}-T_{\text {cabin }} \boldsymbol{s}_{\text {air,WS out }}\right)
\end{aligned}
$$

and

$$
\dot{m}_{\text {air }, \text { WSout }}=q \dot{m}_{\text {water }, \text { HXout }}=q k \dot{m}_{\text {water, }, \text { anout }}
$$

2. Avionics Air Assembly

The structures of the CCAA and the AAA are relatively similar. The AAA also contains a ventilation fan and a condensing heat exchanger which have an exergy balance form as follows:

and

$$
\begin{gathered}
\dot{X}_{d e s, A A A \text { Fan }}=\dot{\mathrm{W}}_{\text {AAA Fan }}-\left(\mathbf{1}-\frac{\boldsymbol{T}_{\text {cabin }}}{\boldsymbol{T}_{\text {Fan }}}\right) \dot{\boldsymbol{Q}}_{\text {AAA Fan }}-\dot{m}_{\text {air, AAA fanout }}\left(\left(\boldsymbol{h}_{\text {air }, \text { AAA Fan Out }}-\right.\right. \\
\left.\left.T_{\text {cabin }} \boldsymbol{S}_{\text {air,AAA Fan Out }}\right)-\left(\boldsymbol{h}_{\text {air, AAA Fan in }}-T_{\text {cabin }} \boldsymbol{S}_{\text {air }, \text { AAA Fan in }}\right)\right)
\end{gathered}
$$

$$
\begin{aligned}
& \dot{X}_{D E S, A A A C H X}=\dot{m}_{\text {air,AAA fanout }}\left(\left(h_{\text {air,AAA CHX in }}-T_{\text {cabin }} s_{\text {air }, A A A C H X} \text { in }\right)-\left(h_{\text {air,AAA CHX out }}-\right.\right. \\
& \left.\left.T_{\text {cabin }} S_{\text {air,AAA CHX out }}\right)\right)-\left(\frac{T_{\text {cabin }}-T_{\text {coolant }}}{T_{\text {coolant }}}\right) \dot{Q}_{\text {AAA TCS }}
\end{aligned}
$$

3. Intermodule Ventilation

The IMV system uses a fan for air recirculation as well. The IMV system may be modeled from an exergy perspective as follows:

$$
\begin{gathered}
\dot{X}_{d e s, I M V \text { Fan }}=\dot{\mathrm{W}}_{I M V \text { Fan }}-\left(\mathbf{1}-\frac{\boldsymbol{T}_{\text {cabin }}}{\boldsymbol{T}_{\text {Fan }}}\right) \dot{\boldsymbol{Q}}_{\text {IMV Fan }}-\dot{m}_{\text {air,IMV fanout }}\left(\left(\boldsymbol{h}_{\text {air,IMV Fan Out }}-\right.\right. \\
\left.\left.T_{\text {cabin }} \boldsymbol{S}_{\text {air, IMV Fan Out }}\right)-\left(\boldsymbol{h}_{\text {air, IMV Fan in }}-T_{\text {cabin }} \boldsymbol{S}_{\text {air }, I M V \text { Fan in }}\right)\right)
\end{gathered}
$$

\section{Particulate Matter Filtration}

The particulate filters within the THC are analyzed from an exergy perspective as the changes in deposit mass kinetic energy as follows:

$$
\dot{X}_{D E S, H E P A}=\dot{m}_{\text {air }, H E P A}\left(\frac{V_{H E P A, o u t}^{2}}{2}-\frac{V_{H E P A, i n}^{2}}{2}\right)-\dot{m}_{\text {deposit }, H E P A}\left(\frac{V_{H E P A, i n}^{2}}{2}\right)
$$

\section{E. Exergy Analysis of the Water Recovery and Management Subsystem}

The purposes served by the WRM subsystem are to distribute potable water for crew utilization, and to collect wastewater for processing. The system effectively monitors water quality, generates a potable water supply for both consumption and for hygiene purposes, and processes wastewater and urine. Wastewater consists of condensate from the THC system, hygiene return water, pretreated urine, and wastewater from the Extravehicular Mobility Unit. ${ }^{20}$ For modelling the WRM subsystem from an exergy perspective, we analyze the urine processor assembly, water processor, 
condensate storage assembly, fuel-cell water storage tanks, wastewater vent assembly, electrical work performed by the system, and water distribution network. Equation 41 describes the rate at which exergy is destroyed within the WRM subsystem.

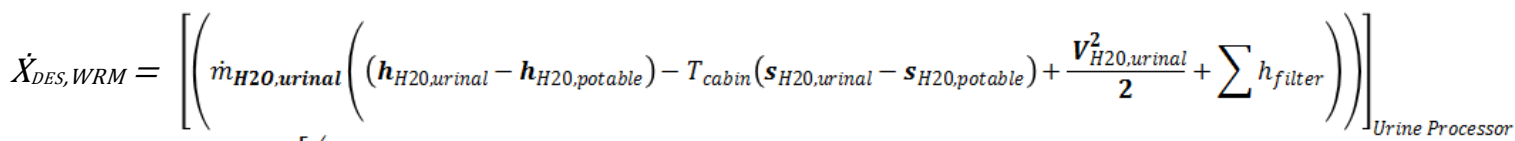

$$
\begin{aligned}
& +\left[\left(\dot{m}_{H 20, \text { urinal }}\left(\left(\boldsymbol{h}_{H 20, \text { urinal filter }}-\boldsymbol{h}_{H 20, \text { potable }}\right)-T_{\text {cabin }}\left(\boldsymbol{s}_{H 20, \text { urinal filter }}-\boldsymbol{s}_{H 20, \text { potable }}\right)+\frac{\boldsymbol{V}_{H 20, \text { urinal }}^{2}}{\mathbf{2}}\right)\right.\right. \\
& +\dot{m}_{H 20, \text { hygiene }}\left(\left(\boldsymbol{h}_{H 20, \text { hy giene filter }}-\boldsymbol{h}_{H 20, \text { potable }}\right)-T_{\text {cabin }}\left(\boldsymbol{s}_{H 20, \text { hygiene filte }} r-\boldsymbol{s}_{H 20, \text { potable }}\right)+\frac{\boldsymbol{V}_{H 20, \text { hy giene filter }}^{2}}{\mathbf{2}}\right) \\
& \left.\left.+\dot{m}_{H 20, \text { cabin }}\left(\left(\boldsymbol{h}_{H 20, \text { cabin filter }}-\boldsymbol{h}_{H 20, \text { potable }}\right)-T_{\text {cabin }}\left(\boldsymbol{s}_{H 20, \text { cabin }}-\boldsymbol{s}_{H 20, \text { potable }}\right)+\frac{\boldsymbol{V}_{H 20, \text { cabin }}^{2}}{\mathbf{2}}\right)\right)\right]_{H 20 \text { Processor }} \\
& +\left[\dot{m}_{H 20, \text { processed }}\left(\frac{\boldsymbol{V}_{H 20, \text { processed }}^{2}}{2}\right)\right]_{\text {storage }} \\
& -\left[\dot{m}_{H 20, v e n t}\left(\left(\boldsymbol{h}_{H 20, v e n t}-\boldsymbol{h}_{H 20, \text { potable }}\right)-T_{\text {cabin }}\left(\boldsymbol{s}_{H 20, \text { vent }}-\boldsymbol{s}_{H 20, \text { potable }}\right)+\frac{\boldsymbol{V}_{H 20, \text { vent }}^{2}}{\mathbf{2}}\right)+\left(1-\frac{T_{\text {cabin }}}{T_{\text {space }}}\right) \dot{\boldsymbol{Q}}_{H 20}\right]_{\text {vent }} \\
& +\left[\dot{m}_{H 20, p o t a b l e}\left(\frac{\boldsymbol{V}_{\text {H20,potable }}^{2}}{2}\right)\right]_{\text {potable }}+\dot{\mathrm{W}}_{\text {elec }}
\end{aligned}
$$

\section{F. Exergy Analysis of the Waste Management Subsystem}

The Waste Management (WM) subsystem consists of commode and urinal, blower, piston, plenum filter, and output filter. Cabin air is pulled through the commode seat to draw in feces through the waste canister. The blower engages once the seat is lifted and operates for about thirty seconds after the seat lid is closed. The piston operates to compress feces collected in a plastic collection bag placed in the waste canister. Canisters are replaced regularly, and a filter lid is placed on the canister. Canisters are then stored for a return to Earth. ${ }^{20}$ The rate of Exergy destroyed within the urinal and commode may be modeled as follows:

$$
\begin{gathered}
\dot{X}_{\text {desWM }}=\left[\dot{m}_{\text {urine,crew }}\left(\left(h_{\text {pretreat filter }}-h_{H 20, \text { potable }}\right)-T_{\text {cabin }}\left(s_{\text {pretreat filter }}-s_{H 20, \text { potable }}\right)+\frac{V_{\text {urine,crew }}^{2}}{2}\right)+\left(1-\frac{T_{\text {cabin }}}{T_{\text {urine }}}\right) \dot{Q}_{\text {urine }}\right]_{\text {Urinal }} \\
+\left[\dot{m}_{\text {commode,crew }}\left(\left(h_{\text {commode,crew }}-h_{\text {commode,cabin }}\right)-T_{\text {cabin }}\left(s_{\text {commode,crew }}-s_{\text {commode,cabin }}\right)\right)+\left(1-\frac{T_{\text {cabin }}}{T_{\text {waste }}}\right) \dot{Q}_{\text {waste }}\right]_{\text {commode }}
\end{gathered}
$$

The waste management blower may be modeled from an exergy perspective as follows:

$$
\begin{aligned}
& \dot{X}_{D E S, W M \text { Blower }}=\dot{W}_{W M \text { Blower }}-\left(1-\frac{T_{\text {Cabin }}}{T_{\text {Blower }}}\right) \dot{Q}_{W M \text { Blower }} \\
& -\dot{m}_{\text {air }, W M \text { Blower out }}\left(\left(h_{\text {air,WM Blower }}-T_{\text {Cabin }} S_{\text {air }, W M \text { Blower out }}\right)-\left(h_{\text {air }, W M \text { Blower in }}-T_{\text {cabin }} S_{\text {air }, W M B \text { Blower in }}\right)\right)
\end{aligned}
$$

The rate of exergy destroyed by the waste management piston may be modeled as follows:

$$
\begin{aligned}
& \dot{X}_{D E S, W M \text { PISTON }}=\dot{\mathrm{W}}_{W M \text { Piston }}-\dot{\mathrm{m}}_{\text {WM Piston }}\left(\left(u_{\text {air }, W M \text { Piston }}-u_{\text {air }, \text { cabin }}\right)+P_{\text {cabin }}\left(V_{\text {Ool }} l_{W M \text { Piston }}-\right.\right. \\
& \text { Vol } \left.\left.{ }_{\text {cabin Pressure }}\right)-T_{\text {cabin }}\left(s_{\text {air,WM Piston }}-s_{\text {air,cabin }}\right)\right)
\end{aligned}
$$

The rate of exergy destroyed by the waste management plenum filter may be modeled as follows:

$$
\begin{gathered}
\dot{X}_{D E S, W M} \text { PLENUM FILTER } \\
=\dot{m}_{\text {air }, W M \text { Plenum Filter }}\left(\frac{V_{W M \text { Plenum Filter,out }}^{2}}{2}-\frac{V_{W M}^{2} \text { Plenum Filter,in }}{2}\right) \\
-\dot{m}_{\text {deposit }, W M \text { Plenum Filter }}\left(\frac{V_{W M}^{2} \text { Plenum Filter, in }}{2}\right)
\end{gathered}
$$


The rate of exergy destroyed by the waste management output filter may be modeled as follows:

$$
\begin{gathered}
\dot{X}_{D E S, W M} \text { OUTPUT FILTER } \\
=\dot{m}_{\text {air,WM ouput Filter }}\left(\frac{V_{W M}^{2} \text { ouput Filter, out }}{2}-\frac{V_{W M}^{2} \text { ouput Filter, in }}{2}\right) \\
-\dot{m}_{\text {deposit }, \text { WM ouput Filter }}\left(\frac{V_{W M}^{2} \text { ouput Filter, in }}{2}\right)
\end{gathered}
$$

\section{Discussion and Conclusion}

The exergy balance equations developed herein illustrate the universal application of exergy to a diversity of systems. Systems ranging from waste management to oxygen generation are able to be modeled to determine their exergy efficiency. With the correct inputs these equations can provide both system and subsystem efficiencies. This type of analysis enables the system designer to identify areas of concern and where to allocate resources. Future work will examine multiple versions of the ECLS system to determine the efficiencies of the designs. Furthermore the current system will be analyzed using the equations formed in this paper to identify areas for improvement, a critical step in advancing the ECLS system for interplanetary transport.

\section{Acknowledgments}

Funding for this research was provided by the NASA Systems Engineering Research Consortium.

\section{References}

${ }^{1}$ J. A. Camberos and D. J. Moorhouse, Exergy Analysis and Design Optimization for Aerospace Vehicles and Systems, vol. 238. Reston, VA: American Institute of Aeronautics and Astronautics, 2011.

2J. Szargut, Exergy Method: Technical and Ecological Applications. WIT Press, 2005.

${ }^{3}$ R. U. Ayres, L. W. Ayres, and K. Martinás, "Exergy, waste accounting, and life-cycle analysis," Energy, vol. 23, no. 5, pp. 355-363, 1998.

${ }^{4}$ M. A. Rosen and I. Dincer, "Exergy-cost-energy-mass analysis of thermal systems and processes," Energy Convers. Manag., vol. 44, no. 10, pp. 1633-1651, 2003.

${ }^{5}$ M. A. Habib and S. M. Zubair, "Second-law-based thermodynamic analysis of regenerative-reheat Rankine-cycle power plants," Energy, vol. 17, no. 3, pp. 295-301, Mar. 1992.

${ }^{6}$ J. H. Horlock, J. B. Young, and G. Manfrida, "Exergy Analysis of Modern Fossil-Fuel Power Plants," J. Eng. Gas Turbines Power, vol. 122, no. 1, pp. 1-7, Jul. 1999.

${ }^{7}$ H.-Y. Kwak, D.-J. Kim, and J.-S. Jeon, "Exergetic and thermoeconomic analyses of power plants," Energy, vol. 28, no. 4, pp. 343-360, Mar. 2003.

${ }^{8}$ M. A. Rosen and D. S. Scott, "Energy and exergy analyses of a nuclear steam power plant," 1986.

${ }^{9}$ M. A. Rosen, "Energy- and exergy-based comparison of coal-fired and nuclear steam power plants," Exergy Int. J., vol. 1, no. 3, pp. 180-192, 2000.

${ }^{10}$ V. Amati, C. Bruno, D. Simone, and E. Sciubba, "Exergy analysis of hypersonic propulsion systems: Performance comparison of two different scramjet configurations at cruise conditions," Energy, vol. 33, no. 2, pp. 116-129, Feb. 2008.

${ }^{11}$ J. A. Camberos and D. J. Moorhouse, "Systems Engineering in Terms of Exergy," Int. J. Aerosp. Eng., vol. 2009, pp. 1-7, 2009.

${ }^{12}$ J. Doty, J. Camberos, and D. Moorhouse, "Designed Experiments: Statistical Approach to Energy- and Exergy-Based Optimization," in 39th AIAA Fluid Dynamics Conference, American Institute of Aeronautics and Astronautics.

${ }^{13}$ Watson, M.D., Gilbert, A., Mesmer, B., "Launch Vehicle Energy Analysis", Proceedings of the $43^{\text {rd }}$ Structures and Mechanical Behavior, JANNAF, Salt Lake City, UT, December, 2015.

${ }^{14}$ Gilbert, A., Mesmer, B., Watson, M. "Exergy Analysis of Rocket Systems", $9^{\text {th }}$ Annual IEEE International Systems Conference, Vancouver, BC, April, 2015.

${ }^{15}$ P.O. Wieland. "Living Together In Space: The Design and Operation of the Life Support Systems on the International Space Station," NASA.

${ }^{16}$ Takada, K.C., A.E. Ghariani, and S.Van Keuren, “Advancing the Oxygen Generation Assembly Design to Increase Reliability and Reduce Costs for a Future Long Duration Mission”, ICES-2015-115, 45th International Conference on Environmental Control Systems, Bellevue, WA, 2015.

${ }^{17} \mathrm{Ni}$, Meng, Michael KH Leung, and Dennis YC Leung. "Energy and exergy analysis of hydrogen production by a proton exchange membrane (PEM) electrolyzer plant." Energy conversion and management 49.10 (2008): 2748-2756

${ }^{18}$ García-Valverde, R., N. Espinosa, and A. Urbina. "Simple PEM water electrolyser model and experimental validation." international journal of hydrogen energy 37.2 (2012): 1927-1938. 
${ }^{19}$ Choi, Pyoungho, Dmitri G. Bessarabov, and Ravindra Datta. "A simple model for solid polymer electrolyte (SPE) water electrolysis." Solid State Ionics 175.1 (2004): 535-539.

${ }^{20}$ Wieland, Paul O. Living together in space: the design and operation of the life support systems on the International Space Station. Huntsville, AL: National Aeronautics and Space Administration, Marshall Space Flight Center, 1998. 